\title{
Controlled trial of laser photocoagulation of pigment epithelial detachments in the elderly: 4 year review
}

\author{
M J Barondes^, S Pagliarini†, I H Chisholm, A M Hamilton, A C Bird
}

\begin{abstract}
Patients who were enrolled in a controlled treatment trial of laser grid photocoagulation for retinal pigment epithelial detachment as part of age-related maculopathy were reviewed 4 years after entry into the trial. The data imply that the original conclusion that this form of treatment did not improve the visual prognosis at 18 months was also justified at 4 years. It has become clear that lesions with evidence of subpigment epithelial new vessels were included in the trial. In a retrospective study the lesions were separated into those in which there was evidence of subretinal neovascularisation and those in which no such evidence existed. A difference was identified in the behaviour of the treated and untreated lesions designated avascular in that the treated eyes had a poorer visual outcome. These cases accounted for the different behaviour between two management groups in the initial study such that the original conclusion that grid photocoagulation of avascular pigment epithelial detachments in the elderly does not improve the visual prognosis is justified.
\end{abstract}

The initial reports on treatment of retinal pigment epithelial detachments (PEDs) by photocoagulation appeared to imply therapeutic benefit to the patients. The technique involved photocoagulation of the temporal periphery of the lesion with light from a xenon arc' or laser. ${ }^{2}$ Subsequently a grid of applications over the surface of the lesion was adopted as the preferred management. ${ }^{3}$ The mechanism by which the PED was caused to flatten was unknown although subsequent evidence implies that reducing the fluid pumped by the pigment epithelium towards the choroid from retina or disruption of the deposits on the inner surface of Bruch's membrane may have contributed to the observed effect.

Although these early studies were encouraging it is evident that many patients treated were young and did not have the poor untreated prognosis of age-related macular disease.$^{45}$ For this reason a randomised treatment trial of avascular PED was undertaken in patients older than 50 years who also had other signs of agerelated maculopathy. A grid pattern of argon laser photocoagulation was used. Recruitment was terminated after 18 months when early results showed greater visual loss in treated eyes than in untreated controls. ${ }^{6}$ The validity of this study as it pertains to 'avascular' lesions is in doubt since many of the patients recruited to the study had indirect evidence of subpigment epithelial new vessels.

The patients have now been reviewed over a 4 year period so that the long term behaviour of the treated and untreated groups can be compared. The entry angiograms have been reassessed as to the presence or absence of new vessels using revised criteria ${ }^{7}$ to identify whether or not the conclusion concerning the benefits of photocoagulation is justified.

\section{Materials and methods}

The entry fluorescein angiograms and subsequent records of patients enrolled in the Moorfields treatment trial of PEDs was reviewed. After suspension of the trial patients were asked to return at 2 years and then yearly. Visual acuity, morphological appearance, fundus photographs, and fluorescein angiograms were assessed at each visit. Visual acuity was always measured in the same room with best correction by a worker who was masked from the form of management.

Forty nine eyes were included in the original treatment trial. Two patients who died before the 6 month visit and one who was lost to follow up before the 18 month visit were excluded from the review. Another four photographic files could not be located, leaving 42 eyes in 42 patients available for review. Of these $20 \mathrm{had}$ been treated and 22 were controls. Visual and morphological outcomes were reviewed.

The lesions were reclassified as to the likely presence or absence of subpigment epithelial new vessels. The following criteria were used to indicate their presence: haemorrhage, exudate, irregular fluorescence not explained by irregular pigmentation of the detached tissues, early and pronounced hyperfluorescence at the edge of the lesion, a notch, and hyperfluorescence beyond the edge of a lesion at the site of a notch. ${ }^{2}$ The behaviour of the treated and untreated lesions was compared in the two groups using Student's $t$ test.

\section{Results}

VISUAL ACUITY

The review study attendances of the treated $(n=$ $20)$ and untreated $(n=22)$ patients were similar. Of the 20 treated patients 18 attended the 18 month visit as did 21 of the 22 observed patients (Table 1). At the 4 year visit 15 of the $20(75 \%)$ treated patients and 19 of $22(86 \%)$ untreated patients were seen. Data beyond 4 years was not considered since half of the patients did not return for their 5 and 6 year visits.

In the treated eyes visual acuity loss occurred early with a mean loss of $2 \cdot 16$ lines at the 3 month visit. This loss remained stable during the first 18 months of review and slowly declined thereafter. 
Control eyes showed gradual but progressive visual loss throughout the period of review (Table 1). The difference between the two groups narrowed with time; a difference was still present at 2 years but was not seen at 4 years.

Visual acuity less than 6/24 was more common in treated eyes than in control eyes at 3 months and 2 years but by 4 years the numbers were similar in the two groups (Table 2).

\section{MORPHOLOGICAL OUTCOME}

Geographic atrophy was more common and occurred earlier in the treated eyes whereas the numbers with subretinal new vessels and tears of the retinal pigment epithelium in the two groups were similar (Table 3 ). In the treated eyes tears

Table 1 Attendance and visual loss in treated and untreated eyes

\begin{tabular}{|c|c|c|c|c|c|c|}
\hline \multirow[b]{2}{*}{ Visit } & \multicolumn{2}{|c|}{ Treated } & \multicolumn{2}{|c|}{ Untreated } & \multirow[b]{2}{*}{$t$} & \multirow[b]{2}{*}{$p$} \\
\hline & No. & $\begin{array}{l}\text { Lines } \\
\text { lost }\end{array}$ & No. & $\begin{array}{l}\text { Lines } \\
\text { lost }\end{array}$ & & \\
\hline $\begin{array}{l}\text { Initial } \\
3 \text { month } \\
6 \text { month } \\
9 \text { month } \\
1 \text { year } \\
1.5 \text { year } \\
2 \text { year } \\
3 \text { year } \\
4 \text { year }\end{array}$ & $\begin{array}{l}20 \\
19 \\
18 \\
16 \\
18 \\
18 \\
19 \\
15 \\
15\end{array}$ & $\begin{array}{l}- \\
2 \cdot 16 \\
2 \cdot 50 \\
2 \cdot 50 \\
2 \cdot 44 \\
2 \cdot 66 \\
3 \cdot 21 \\
2.93 \\
3.33\end{array}$ & $\begin{array}{l}22 \\
20 \\
22 \\
18 \\
20 \\
21 \\
19 \\
19 \\
19\end{array}$ & $\begin{array}{l}- \\
0 \cdot 30 \\
0 \cdot 68 \\
0 \cdot 72 \\
0.95 \\
1 \cdot 13 \\
1.79 \\
2.42 \\
3.37\end{array}$ & $\begin{array}{l}2823 \\
2857 \\
2622 \\
2199 \\
1959 \\
1699 \\
0.697 \\
-0.0444\end{array}$ & $\begin{array}{l}0.008 \\
0.0079 \\
0.013 \\
0.034 \\
0.058 \\
0.098 \\
0.491 \\
0.965\end{array}$ \\
\hline
\end{tabular}

$t=$ Student's $t$ test; $p=$ provability of error.

Table 2 The number of eyes with vision worse than $6 / 24$ in treated and untreated eyes

\begin{tabular}{llrllr}
\hline & \multicolumn{2}{l}{ Treated eyes } & & \multicolumn{2}{l}{ Untreated eyes } \\
\cline { 2 - 3 } \cline { 5 - 6 } Visit & Patients & $V A<6 / 24$ & & Patients & $V A<6 / 24$ \\
\hline 3 months & 19 & $7(36 \%)$ & & 20 & $2(10 \%)$ \\
2 years & 19 & $11(57 \%)$ & & 19 & $7(36 \%)$ \\
4 years & 15 & $10(66 \%)$ & 19 & $14(73 \%)$ \\
\hline & & &
\end{tabular}

Table 3 Visual acuity (VA) in Snellen's lines loss compared with morphological outcome

\begin{tabular}{|c|c|c|c|c|c|c|}
\hline \multirow[b]{2}{*}{ Outcome } & \multicolumn{3}{|l|}{ Treated } & \multicolumn{3}{|c|}{ Untreated } \\
\hline & No. $(\%)$ & Onset* & $V A$ loss & No. (\%) & Onset * & $V A$ loss \\
\hline $\begin{array}{l}\text { Geographic atrophy } \\
\text { SRN } \\
\text { Persistent PED } \\
\text { RPE tear }\end{array}$ & $\begin{array}{l}10(50) \\
8(40) \\
0 \\
2(10)\end{array}$ & $\begin{array}{l}1 \\
2 \cdot 3 \\
\overline{0} \cdot 25\end{array}$ & $\begin{array}{l}2 \cdot 6 \\
4 \cdot 9 \\
\overline{5} \cdot 0\end{array}$ & $\begin{array}{r}5(23) \\
10(50) \\
5(23) \\
2(9)\end{array}$ & $\begin{array}{l}3 \cdot 8 \\
2 \cdot 2 \\
4 \cdot 0 \\
0 \cdot 5\end{array}$ & $\begin{array}{l}2 \cdot 6 \\
4 \cdot 3 \\
1 \cdot 0 \\
5 \cdot 0\end{array}$ \\
\hline
\end{tabular}

$\star=$ Onset in years after entry into trial. $\mathrm{SRN}=$ subretinal neovascularisation. $\mathrm{PED}=$ pigment epithelia detachment. RPE $=$ retinal pigment epithelium.

Table 4 Snellen's lines visual acuity loss in those patients in whom categorisation as vascular and avascular was unanimous

\begin{tabular}{llllll}
\hline \multirow{2}{*}{$\begin{array}{l}\text { Review } \\
\text { (years) }\end{array}$} & \multicolumn{2}{l}{ Voscular PEDs } & & \multicolumn{2}{l}{ Avascular PEDs } \\
\cline { 2 - 3 } \cline { 5 - 6 } & Treated & Control & & Treated & Control \\
\hline 0.25 & -2.20 & $-0.50 \dagger$ & & -4.83 & $-0.17^{\star}$ \\
0.50 & -2.75 & -1.75 & & -4.50 & $-0.29^{\star}$ \\
0.75 & -3.00 & -2.67 & & -4.40 & $-0.50^{\star}$ \\
1.00 & -3.00 & -3.75 & & -4.67 & $-0.33^{\star}$ \\
1.50 & -3.40 & -4.00 & & -4.50 & $-0.29^{\star}$ \\
2.00 & -4.60 & -4.66 & & -4.33 & $-0.20 \dagger$ \\
3.00 & -4.75 & -4.66 & & -3.60 & $-0.33 \dagger$ \\
4.00 & -4.75 & -5.60 & & -3.80 & $-1.17 \ddagger$ \\
\hline
\end{tabular}

${ }^{\star} \mathrm{p}<0.001 ; \uparrow \mathrm{p}<0.01 ; \ddagger \mathrm{p}=0.01$ appeared soon after therapy whereas in the control eyes they occurred at some time during the first year after recruitment to the trial. Persistent detachment of the retinal pigment epithelium was seen only in those patients who were untreated. These eyes had a favourable course losing only 1.00 line of acuity at the time of the last review whether or not there was indirect evidence of subpigment epithelial new vessels. This is in contrast to those with new vessels clearly seen in the subretinal space and atrophy or tears of the RPE which gave poor vision.

\section{CORRELATION WITH INITIAL CLASSIFICATION}

There were 10 lesions which were classified as vascular by all three readers.' Of these six received grid photocoagulation. The two groups behaved in a similar fashion after therapy although acuity was lost slightly more quickly in those who were treated (Table 4). The major loss of acuity was within the first 3 months in these patients whereas in the controls the loss occurred over the first year.

Thirteen lesions were designated as avascular; six were treated and seven untreated. In the treated group major visual loss occurred in the initial 3 months after photocoagulation. This was due to tears of the pigment epithelium or to atrophy which accompanied flattening. By contrast the controls had little loss of acuity until the fourth year. Despite the small numbers the deficit in the treated patients was significantly greater than in the controls up to 3 years after entry into the trial.

\section{Discussion}

The controlled trial showed that there is substantial risk of early visual loss in treated eyes by 18 months. A 2 line reduction in Snellen acuity was recorded in $73 \%$ of eyes randomised to treatment and $41 \%$ of untreated eyes. The early results from this study discouraged many ophthalmologists from treating avascular PEDs.

After 4 years of review convergence of visual acuity in the two groups is attributable to gradual worsening of vision of the untreated eyes rather than to delayed improvement in the treated eyes. The equilibration of visual loss might be expected considering the natural history of untreated PEDs in the elderly. The extent of visual loss in the untreated eyes is similar to that reported previously. ${ }^{8-13}$ Treatment apparently hastened the visual loss that would otherwise occur at a slower pace.

The morphological outcome of treatment and control eyes differed. Persistent detachment occurred exclusively in untreated eyes; the retention of good visual acuity (one line of acuity lost) in these eyes has been reported." Tears of the pigment epithelium may complicate treated or untreated PEDs ${ }^{14}$ and did occur with similar frequency in treated and untreated eyes. It appears that treatment precipitates a tear in a lesion which is predisposed to such a complication rather than causes an event which would not otherwise have occurred. The incidence of subretinal neovascularisation in both groups was 
similar and is within the range of 24 to $67 \%$ cited by others..$^{8-131516}$ It is also implied that subpigment epithelial neovascularisation is not an inevitable association or consequence of PEDs. The incidence of atrophy was higher in treated eyes $(50 \%)$ than in the control eyes $(23 \%)$ and was associated with visual loss. Atrophy occurred soon after treatment in the treated eyes while the onset in control eyes was delayed until the third or fourth year when it followed spontaneous flattening of the detachment. Evidence suggests that metabolic failure of the RPE may be responsible for resolution of the detachment and the ensuing geographic atrophy. ${ }^{131718}$ Destruction of the RPE by laser photocoagulation might hasten or exaggerate this process.

The objective of the original controlled trial was to test the benefits of grid laser treatment on avascular PEDs but the analysis indicates that a heterogeneous group of patients was recruited into the study. ${ }^{7}$ This review showed that many entry angiograms showed signs believed to imply the presence of new vessels and it was in these lesions that new vessels appeared. On extended follow up $55 \%$ of the patients developed subretinal neovascularisation. Although the numbers in which all three observers agreed on reclassification of lesions are small there is no indication to modify the original conclusion that grid laser photocoagulation, as undertaken in the original trial, does not improve the visual prognosis in 'avascular' retinal pigment epithelial detachments as a manifestation of age-related maculopathy. The major difference in behaviour of the treated and control groups as previously reported $^{6}$ was early loss of visual acuity in the former. It appears that those lesions redesignated as avascular accounted exclusively for this difference in response. A treatment method which flattens detachments while producing minimal tissue damage might preserve vision more effectively. This does not prove that other techniques of photocoagulation would not be successful ${ }^{20}$ but emphasises the desirability of a different approach to therapy.
S Pagliarini is supported by British Council Grant ITA/2281/199.

1 Jepson CN, Wetzig. Photocoagulation in disciform macular degeneration. Am $\mathcal{F}$ Ophthalmol 1969; 67: 920-30.

2 Zweng HC, Little HL, Peabody RR. Laser photocoagulation of macular lesions. Trans Am Acad Ophthalmol Otolaryngol 1968; 72: 377-88.

3 L'Esperance FA. Argon and ruby photocoagulation of disciform macular lesions. Trans Am Acad Ophthalmol Otolaryngol 1971; 75: 609-25.

4 Lewis ML. Idiopathic serous detachment of the retinal pigment epithelium. Arch Ophthalmol 1978; 96: 620-4.

5 Meredith TA, Brailey RE, Aaberg TM. Natural history of serous detachments of the retinal pigment epithelium. Am $\mathcal{F}$ Ophthalmol 1979; 88: 643-51.

6 The Moorfields Macular Study Group. Retinal pigment epithelial detachments in the elderly: a controlled trial of argon laser photocoagulation. Br $\mathcal{F}$ Ophthalmol 1981; 66: argon

7 Pagliarini S, Barondes MJ, Chisholm IH, Hamilton AM, Bird AC. Detection of subpigment epithelial neovascularisation in retinal pigment epithelial detachments: a review of the Moorfields treatment trial. Br f Ophthalmol 1992; 76: 8-10.

8 Meredith TA, Braley RE, Aaberg TM. Natural history of serous detachments of the retinal pigment epithelium. $A m \mathcal{F}$ Ophthalmol 1979; 88: 643-51.

9 Braustein RA, Gass JDM. Serous detachments of the retinal pigment epithelium in patients with senile macular disease. Am f Ophthalmol 1979; 88: 652-60.

10 Klein ML, Obertynski H, Patz A, Fine SL, Kini M. Followup study of detachment of the retinal pigment epithelium. up study of detachment of the re

11 Casswell AG, Kohen D, Bird AC. Retinal pigment epithelial detachments in the elderly: classification and outcome. $\mathrm{BrF}$ Ophthalmol 1981; 69: 397-403.

12 Poliner LS, Olk RJ, Burgess D, Gordon ME. Natural history of retinal pigment epithelial detachments in age-related macular degeneration. Ophthalmology 1986; 93: 543-50.

13 Elman MJ, Fine SL, Murphy RP, Patz A, Auer C. The natural history of serous retinal pigment epithelium detachment in patients with age-related macular degeneration. Ophthalmology 1986; 93: 224-30.

14 Hoskin A, Bird AC, Sehmi K. Tears of detached retinal pigment epithelium. Brf Ophthalmol 1981; 65: 417-22.

15 Teeters VW, Bird AC. The development of neovascularization of senile disciform macular degeneration. Am $\mathcal{F}$ Ophthalmol 1973; 76: 1-18.

16 Ho PC, Namperumalsamy P, Pruett RC. Photocoagulation of serous detachments of the retinal pigment epithelium in patients with senile macular disease. Ann Ophthalmol 1984; patients with $213-8$.

17 Bird AC, Marshall J. Retinal pigment epithelial detachments in the elderly. Trans Ophthalmol Soc UK 1986; 105: 674 82.

18 Chuang EL, Bird AC. The pathogenesis of tears of the retinal pigment epithelium. Am f Ophthalmol 1988; 105: 285-

19 Singerman LJ. Laser photocoagulation of choroidal new vessel membrane complicating age-related macular degeneration membrane complicating age-related macular degeneration 8: $115-21$.

20 MaGuire JI, Benson WE, Brown GC. Treatment of foveal pigment epithelial detachments with contiguous extrafoveal neovascular membranes. Am $\mathcal{f}$ Ophthalmol 1990; 109 523-9. 